AperTO - Archivio Istituzionale Open Access dell'Università di Torino

\title{
Derivational networks in Italian
}

\section{This is a pre print version of the following article:}

Original Citation:

\section{Availability:}

This version is available http://hdl.handle.net/2318/1744294

since 2020-07-20T09:09:00Z

Publisher:

De Gruyter Mouton

Published version:

DOI:10.1515/9783110686630-025

Terms of use:

Open Access

Anyone can freely access the full text of works made available as "Open Access". Works made available under a Creative Commons license can be used according to the terms and conditions of said license. Use of all other works requires consent of the right holder (author or publisher) if not exempted from copyright protection by the applicable law. 


\section{Contributor Metadata Approval Sheet/Contributor Contract/Proof}

\section{Dear Contributor(s),}

Thank you for publishing with us! Please find enclosed your Contributor proof. In order to process your contribution, we kindly request that you carefully check your Contributor metadata on the following pages, and then indicate the conclusion of an Contributor Contract with us by setting checkmarks and dates in designated boxes. The Contributor Contract consists of the cover page "Contributor Contract", the Metadata Approval Sheet and the General Terms and Conditions for Contributor Contracts. Any provisions previously agreed upon in writing shall retain their validity. Finally, we kindly ask you to check and correct the proofs of your article. Please check the metadata of all contributors to your chapter carefully.

Important: The box Checked and confirmed: Contributor Metadata and Contributor Contract must be checked and dated in order for your contribution to be published. You will find both boxes directly after the Metadata Approval Sheet.

We need your postal and email address for Abstracting- and Indexing Services, and sending you free print copies or offprints if applicable. Your address will be included in the HTML metadata of the article and will appear in the PDF of the printed work if standard for the volume. This data is necessary for the automatic delivery of Contributor PDFs.

Thank you for your cooperation!

De Gruyter 


\title{
CONTRIBUTOR CONTRACT
}

\author{
Between \\ De Gruyter \\ and \\ Corresponding Contributor \\ Livio Gaeta
}

Regarding

Chapter Title:

Derivational networks in Italian

Chapter DOI:

10.1515/9783110686630-025

Book Title:

Derivational Networks Across Languages

a Contributor Contract has been concluded. Details regarding the Contributor Contract are specified in the attached General Terms and Conditions for Contributor Contract. 


\section{Contributor Metadata Approval Sheet}

Book title: Derivational Networks Across Languages

Chapter DOI: 10.1515/9783110686630-025

Chapter title: Derivational networks in Italian

Please check the metadata carefully. You will find already available details in the second column. If they need to be changed, please enter the updated information in the third column.

\section{Contributor 1}

\begin{tabular}{|r|l|l|}
\hline Corresponding address according to available information & To be changed \\
\hline Salutation* (Mr/Ms/other) & & Mr \\
\hline Title* & & Prof. Dr. \\
\hline Surname* & Gaeta & \\
\hline First Name* & Livio & \\
\hline E-Mail* & & livio.gaeta@ unito.it \\
\hline Corresponding Author* (yes/no) & yes & \\
\hline
\end{tabular}

The given address is a(n) $\quad \square$ affiliation. $\quad \square$ privat address.

(For privat address omit Institution and Department!)

\begin{tabular}{|r|l|l|}
\hline Institution & University of Turin \\
\hline Department & Department of Humanistic Studies \\
\hline Number* & Street* & Via S. Ottavio \\
\hline ZIP Code* & 10124 \\
\hline City* & Turin \\
\hline State & Italy \\
\hline Country* & & \\
\hline
\end{tabular}

*required

$\checkmark$ I would like to receive a notification when my contribution appears online and I would like to download a PDF copy. I accept that the corresponding details will be transfered to Abstracting und Indexing Services to improve the findability of my contribution in the internet. I note that my details might be displayed on the De Gruyter webpage, but only if they are part of my contribution. (Thus a full postal address and an email address is needed!)

$\square$ I don't want to receive a notification when my contribution appears online and I don't want to download a PDF copy. My contact details may not be transfered to Abstracting and Indexing Services and they may not be displayed in print or De Gruyter webpage. 


\section{Checked and confirmed:}

Contributor Metadata and Contributor Contract

(By inserting the checkmark you confirm the conclusion of the Contributer Contract for your contribution.)

Date 13.3.2020 


\section{GENERAL TERMS AND CONDITIONS FOR CONTRIBUTOR CONTRACT}

These General Terms and Conditions are an integral part of your Contributor Contract. The individual details of your agreement with us can be found on the sheet titled Contributor Contract.

Our goal as a publisher is to be a competent partner to our contributors and to facilitate the quality, reach, reputation, and validity of their work. In order to do so, both parties must commit to a set of rules as follows:

\section{Definitions}

You: You as the Contributor of the Work. When there is more than one Contributor, the term "You" shall apply collectively and the provisions set out in these terms and conditions apply equally to all Contributors.

We: the Walter De Gruyter GmbH Publisher named in your Contributor Contract.

Work: the content to be published as printed and electronic edition.

Contributor Contract: the actual agreement, which is issued to you as a cover page to these term and conditions.

2 Your Rights and Obligations

2.1 Grant of Rights: As a publisher, we take copyright very seriously. We must make sure that we have the right to use all parts of your Work. You warrant that you own the manuscript, an that you are free to assign the rights without restriction and have acquired the rights to any content as necessary. This applies to all parts, including any illustrations, indices, tables, textual excerpts, multimedia components, etc. Further, you warrant that you have not assigned any rights that would conflict with the rights granted to us in this contract. You guarantee that your work, including all parts, does not infringe on any rights such as copyrights, performing rights, trademarks, rights of privacy, or other third-party rights. You agree to reimburse us fo any costs or liabilities resulting from a breach of these warranties.

2.2 Publication Elsewhere: In order to support the marketing strategy for your Work, you agre not to publish the Work (or a substantially equivalent work) or make it otherwise available to the public without first obtaining our written consent.

2.3 Repository Policy: You are free to self-archive up to $10 \%$ of the Work (with the exception of textbooks and databases) on your own website or in the repository of your university or institution. In addition, you may place a link to the product page of your Work on ou website www.degruyter.com in public repositories that allow a redirect. You can find a complete list in the Rights and Licenses section of our website.

2.4 VG Wort: As the laws regarding the German collecting society VG Wort are subject to frequent change, we include here a translation of the recommended wording for contributo agreements provided by the German Publishers and Booksellers Association on exercising your rights through VG Wort. In the following paragraphs, you assign to us the right to exercise our rights with VG Wort. In order for you to profit from the copyright-holder share of the VG Wort distribution, you must sign an agreement directly with VG Wort as well as register your Work upon publication. You may then decide if you would like to let us, as a publisher, participate in the distribution of those proceeds as well. We will provide more detailed information in a separate communication when your Work is published. We retai the right to make changes to the following paragraphs as a result of court rulings or changes to the law.

The Author grants to the Publisher, for the duration of the contract, all usage rights that may be exercised at collecting societies such as VG Wort and VG Bild-Kunst according to their contractual stipulations. The granting of these rights serves the purpose of registration at the collection societies for mutual exercising of rights. The proceeds from the exercising of rights are distributed by the collecting societies according to \$27 Abs. 2 VGG and according to the shares defined in their distribution plan, and are distributed directly to copyright holders and publishers. The Author agrees that he or she must conclude an agreement directly with the collecting society in order to receive the (copyright-holder) share of the distribution.

With regard to the statutory reimbursement claims stated in $\$ 63$ a Satz 1 UrhG, the following ap plies if the Author is registered to exercise rights through the VG Wort: the Author can, accordin to $\$ 27$ a VGG, either upon registration or at a later time following publication, grant consent at the collecting society for the Publisher to participate in the proceeds from the statutory reimbursement claims. The amount of the publisher share is based on the current distribution plan of the individual collecting society. If the Author is not registered to exercise rights, the Publisher can receive a share of the distribution from collecting societies (publisher share) for the statutory reimbursement claims stated in \$63a Sentence 1 UrhG only in the case that the Author has transferred these claims to the Publisher after the publication of the work.

3 Grant of Rights

3.1 Rights of Use: You assign to us, for the purpose of ensuring the optimal distribution and availability of your work the right:

a) To reproduce, distribute, and make available your Work in printed form including as print-on-demand;

b) To produce machine-readable forms of your Work (including digitization) and to store it electronically in all storage media, including in our own databases and those of third parties, such as Amazon or Google;

c) To make your Work available in part with "look inside" functionality, for example on Amazon or Google; d) To reproduce and make available your Work in electronic form, particularly as eBook, database, and/or other forms of electronic media and within the scope of internet services or other online uses or in interactive multimedia production;

e) To make your Work available in public or closed user groups at the location and time of their choice (for example, eBook use in libraries) as well as reproducing it on monitors or other scanners and to be printed by the user as many times as the user wishes, in whole or in part, including as prepublication or in excerpt;

f) To reproduce and distribute your Work on any and all data carriers, for example DVD, CD-Rom, flash drive.

3.2 Ancillary Rights: You also assign to us, for the purpose of optimally exercising the rights to your Work, the right:

a) To translate it into other languages and to use the translation;

b) To print it in whole or in part as a prepublication and/or as subsequent reprint, including in newspapers and periodicals (for example in reviews);

c) To publish it in whole or in part in our other publications or publications of another publisher, including in abridged form;

d) To produce or license as a paperback, or as a popular or special or reprint edition;

e) To reproduce and distribute it in a collected works edition and in compilations, even after 20 years have elapsed since the first publication of the Work;

f) To reproduce and distribute it by all other means, including photocopying, photomechanical reprinting, or as Braille embossing;

g) Of rendition, including rights to recitation, performances, and broadcast in radio or television media or internet;

h) To transfer it, in full or in part, to sound recordings, image or image-sound recordings as well as the right to their reproduction, distribution, and reproduction to the public;

i) To use it in collections for use in church, school, or instructional settings

3.3 Extension of Rights: Unless otherwise specified in the provisions for contributors in the authors section of our website you grant all usage rights and ancillary rights to us as exclusive rights without any restriction as to content or territory for the duration of the copyright. We may exercise these rights but are under no obligation to do so to the extent described here.

3.4 Unknown Types of Use: You grant us the exclusive and permanent rights without any restriction as to content and territory for all forms of media of expression now known or that will be developed in the future. The granting of rights extends to the exercising of rights through us or through the granting of these rights to a third party.

3.5 Transferral to Third Parties: You grant us the right to transfer all rights listed here to third parties and/or to license the Work to third parties. We require these rights in order to fulfil certain sales models such as online use through aggregators (platforms that curate conten for specific usage by customers and give us a share of the proceeds). We naturally require that all licensees provide appropriate attribution to you, the copyright holder.

4 Open Access

In the case that we have mutually agreed to publish your Work as Open Access, the following conditions apply in addition:

4.1 You are free to publish your Work according to a Creative Commons license (https://creativecommons.org), as of a date agreed upon with us. You choose the appropriate license when discussing the contractual details with us (see Contributor Contract). You have the choice between:

a) CC-BY (Attribution)

b) CC-BY-NC-ND (Attribution-NonCommercial-NoDerivatives)

4.2 We will provide you with the final version of your Work as a PDF file. This is the version that is published Open Access.

4.3 We will publish your Work as a freely available eBook on our website under the license you have chosen and which is shown in the Contributor Contract.

4.4 According to the license stated in 6.1, you are of course free to put the eBook version of your Work on your own homepage, a university or institutional repository, or any website of your choice.

5 Manuscript / Content

5.1 General:

a) We and the editors are authorized to change your Work after prior discussion with you, or to ask you to make changes in order to maintain the consistency of the series, the volume, or the database.

b) In addition, to ensure quality of your Work before final acceptance, we are authorized to ask a third party to review the Work. Should revisions be necessary, you will be asked to perform these. Should you be unable or unwilling to do so, we reserve the right to deny acceptance or publication of your Work.

c) Our customers and readers are interested in the most precise information possible regarding your Work. Please inform us immediately as soon as you become aware that you will not be able to deliver by the date agreed upon in the Contributor Contract or that the manuscript deviates by more than $10 \%$ of the length agreed upon.

d) If your Work contains an index, you are required to create an index according to ou technical specifications. If the publication date is delayed by more than 6 weeks as a result of index preparation, we reserve the right to publish the Work without an index. In the electronic version of the Work, the full-text search replaces the need for a separate index.

e) If you cannot adhere to the manuscript length or the submission deadlines agreed upon with you in your Contributor Contract (e. g. delayed delivery of the Work), we reserve the right to set a new deadline or to plan a different form of publication. If the second deadline also cannot be kept, we reserve the right to deny publication or to reduce your royalty. 
5.2 Manuscript for Typesetting

a) This option is for manuscripts that will be professionally typeset. You submit the manuscript to be typeset as an electronic file, usually in the format docx, tex, rtf, or indd. Formulas and tables should not be anchored in the manuscript as images. In addition, we require a PDF file or a definitive printout for comparison including reproducible copies of illustrations / high-resolution image files.

b) After the manuscript has been prepared by our typesetter, we provide you with proofs for corrections. In most cases, you will receive proofs in electronic format as a PDF file or via a web-based online proofing system. We ask for your understanding that we generally provide one set of proofs for correction and a second set of proofs for your approval for printing (imprimatur).

c) The first set of proofs is provided for you to check the manuscript conversion to typesetting. Please check these proofs carefully for any mistakes (e. g., word breaks) that may have occurred during the process. Kindly note that only minor content corrections can be done at this late stage. If the index entries were not already anchored in the manuscript, we will ask you to do this during the first correction stage.

d) The second set of proofs is simply to check that any corrections marked in the first proof run have been carried out, and for you to provide your approval for printing (imprimatur), if need be under the condition that final corrections be carried ou before the work is printed. We will check these final corrections internally in order to ensure punctual publication of your Work. We retain the right to decide when the manuscript is ready to print from a technical and typographical point of view.

e) We ask for your cooperation in keeping the number of corrections at a reasonable and necessary level. Changes to the Work after the submission of the final manuscript are very costly. We cover the cost of corrections up to two per printed page, and reserve the right to charge you if changes made beyond that result in excessive costs and/or if these changes require additional print runs. This does not apply if corrections are required due to errors in the typesetting process or due to new academic findings or legal decisions. Writing and Submitting via a Content Management System (CMS)

f) Particularly in the case of encyclopedias, dictionaries and reference works, which are often published "ahead of print," we may use a so-called Content Management System (CMS), which is individually configured for each Work.

g) We provide the CMS to you, and we request that you use it to write and submit you Work. You will receive an invitation to the system and all relevant supporting guidelines and documentation.

h) Reviews by the series or volume editors or in-house editors as well as manuscript revision and corrections are done directly in the CMS. Please follow the style and content guidelines to avoid unnecessary delays.

i) At the relevant point in the process, you will be contacted to provide your approval fo publication of the content (not the form). Please make only those corrections which are absolutely necessary at this time. Changes to content are no longer possible, as they can no longer be reviewed. If you do not respond to the call for approval by the given deadline, approval will be assumed.

j) We support your work in the CMS with detailed instructions and guidelines, and are personally available if there are problems. Any decisions regarding bug fixes or othe technical issues will be made solely by us.

Publication Subsidy / Open Access Fee

6.1 A publication subsidy may be required for some works to be paid plus VAT if not mutually agreed in the Contributor Contract.

6.2 If we have come to a mutual agreement to publish your Work as Open Access, an Open Access fee is generally required.

6.3 The payment of the publication subsidy or the Open Access Fee is generally due upon publication of the work. The publication subsidy or the Open Access fee is not subject to reimbursement.

6.4 We will be happy to support you in applying for any outside funding by providing any necessary calculations or paperwork, and will fulfil funder requirements.

\section{Free Copies}

If you provide us with your e-mail address you can download a PDF of your contribution from ou website. The number of free print copies is agreed upon in the contract concluded with your editor You may acquire further non-German copies of your own Work as well as all book titles from the publisher, including eBooks, at a discount of $30 \%$ off the retail price. You are also entitled to a discount of $20 \%$ off the retail price of individual subscriptions and single issues of journals. You may not sell free copies or copies purchased at a discount.

\section{Subsequent Editions, Revised Editions}

8.1 A number of factors are relevant when considering a subsequent or revised edition, for example, the economic feasibility of the work, as well as the topicality or the accuracy of the scientific findings.

8.2 Should you wish to publish a new edition of your Work, please inform us and we will review your suggestion in light of the criteria above.

8.3 Should we decide against publishing a new edition of your Work, we will contact you to discuss alternative options.

8.4 Should we decide to publish a new edition of your Work, we will communicate to your ou decision and negotiate with you a publication plan. You agree to revise the Work according to the current state of the academic discussion and submit it to us for publication.

8.5 Should you not be willing or able to perform the revisions yourself, you may suggest a third party to us. We agree not to reject this suggestion without good reason. If you do not wish to make a suggestion, we are authorized to assign the revision to a third party.

8.6 In the case of revision by one or more third party/parties, we are entitled but not obligated to continue to use your name in the title of the Work.

\section{$9 \quad$ Remainders}

Because our warehouse capacities are limited, we regularly check if our printed stock can be reduced. Through digitisation and print-on-demand, we can keep the majority of our titles available and in print without keeping physical stock on hand. We reserve the right to pulp or sell any remaining stock at a reduced price.

10 Legal Succession

10.1 The legal situation must be defined in case of succession. Our obligations and duties according to the Contributor Contract will transfer for your heirs in full, with the exception of paragraph 11

10.2 In the event of death before the first edition of the Work is completed, we are entitled to withdraw from this agreement with no claims from your heirs. We may take over the partia manuscript and have it completed by a third party, taking your personal rights into account.

\section{Termination}

11.1 We are entitled to terminate the Contributor Contract in writing with immediate effect if our cooperation on the Work cannot be completed as planned, e. g. if you are unwilling or unable to complete the Work. If we have made substantial investments at the time of termination, all rights assigned remain with us. We reserve the right to reclaim any payments already made to you.

11.2 You are also entitled to terminate the agreement in writing with immediate effect, e. g. if we are liquidated. In this case, all rights revert back to you.

11.3 In the case of termination, we retain the right to continue to distribute any copies of the Work that have already been produced. We may continue to make the electronic version of your Work available on our platform in order to fulfil obligations to customers who have purchased those versions.

11.4 If your Work is published as part of a series or as a contribution to a volume or database, we are entitled to terminate the Contributor Contract with immediate effect if the contract with the editor expires or is terminated, or if the series or database has been terminated. In this case, we will do our utmost to publish your Work as a stand-alone volume or to include it in another series.

11.5 You agree to forgo your extraordinary termination option according to German law for the non-publication of a contribution in a periodical, e. g. yearbook (\$45 Para. 1 Verlagsgesetz)

\section{Data Protection}

We are committed to the responsible handling and processing of the personal data we collect from you. Details can be found in our data protection policy for authors and editors on our website (https://www.degruyter.com/dg/page/privacy/datenschutzerklrung). A printed copy will be provided to you upon request.

\section{General Provisions}

13.1 Unless otherwise agreed upon, all provisions of this agreement are valid and binding for both your legal successors as well as our legal successors.

13.2 Revisions and amendments to the agreement must be made in writing. Oral agreements and declarations have not been made.

13.3 Should individual provisions of this agreement become invalid or unenforceable, this shal not affect the validity of the remaining provisions. You and we are bound to replace the invalid provision with a valid one that corresponds to the purpose and meaning of the invalid one. The same shall be applicable to any gaps in this agreement.

13.4 The laws of the Federal Republic of Germany apply to this agreement, particularly the German Civil Code, German Copyright Law, and German Publishing Law.

13.5 Place of fulfilment and jurisdiction is the location of our headquarters in Berlin, Germany, to the extent legally possible.

Version last revised: 18.10 .2019

Contributor Publication Agreement 


\section{Livio Gaeta}

\section{Derivational networks in Italian}

\subsection{General notes}

With regard to the main questions discussed in the introductory chapter devoted to the Romance languages, a maximization approach has been adopted throughout this chapter on Italian (cf. Grossmann and Rainer 2004 for a detailed description of Italian word-formation). In particular, while - in accordance with the general design of the project - blatant cases of transflection have been left out from the sample (such as bere 'to drink' > bevuta 'drink', discendere 'to descend' > discesa 'descent', nuotare 'to swim' > nuotata 'swim', etc., which directly correspond to the feminine form of their respective past participles: bevuto 'drunk', disceso 'descended', nuotato 'swum', etc.), derivatives like frustata 'lash' and martellata 'hammer blow' have been included because a denominal interpretation is available. This is because of the suffix - ata that is found in denominal nouns like pagliaccio 'clown' > pagliacciata 'farce', which diachronically results from the reanalysis of the feminine past participle of 1st conjugation verbs (cf. Gaeta 2000). In these cases, a double motivation can be appealed to because we might take either the (denominal) verbs frustare 'to lash' and martellare 'to hammer' or the nouns frusta 'whip' and martello 'hammer' as a derivational base, relating the derivatives respectively either to the nominal base (via suffixation) or to the verbal base (via conversion). A similar approach has been adopted for cases in which an adjective can in principle be derived either from a verb via conversion (e.g. occhiello 'eyelet' > occhiellare 'to eyelet' > occhiellato 'eyeletted'), possibly accompanied by prefixation as in osso 'bone' > disossare 'to debone' > disossato 'deboned', or directly from a noun via suffixation (occhiello > occhiell-ato), possibly in combination with prefixation, as in osso > dis-oss-ato, on a par with clearly denominal nouns like fortuna 'luck' > fortun-ato 'lucky' and grazia 'grace' > s-grazi-ato 'ungraceful'. Notice that, in several cases, the intermediate verb does not occur or is rather infrequent with regard to the -ato derivative, as for instance in the case of dente 'tooth' > dent-ato 'dentate' and of the scarcely frequent conversion dentare 'to provide with teeth'. This makes a denominal derivation more plausible.

In accordance with the maximization approach, a number of patterns have also been included in the sample that are traditionally considered at the edge of the continuum between inflection and derivation. This concerns, for instance, the suffix of the so-called absolute superlative -issimo, which is traditionally assigned to inflection but is largely irrelevant for syntax, as shown by a 
comparison with the so-called relative superlative: Gianni è bellissimo 'Gianni is very beautiful' vs. Gianni è il *bellissimo / più bello di tutti 'Gianni is the most beautiful of all' (cf. Gaeta 2003), as well as the old form of the present participle, which has become in fact a suffix for AGENT nouns or adjectives (cf. Luraghi 1999). Finally, all instances of evaluative affixations have been included in the sample in spite of their problematic status with regard to prototypical derivation. A similar maximization approach has also been adopted for the difficult cline running from neoclassical compounding down to affixation. Following Iacobini (2004: 88), elements like inter-, multi-, para-, etc. have been included in the sample as they are commonly held to share the same properties of the prefixes with which they often form paradigmatic series. In contrast, other combining forms such as tele-, video-, -fero, -logo, etc. have been excluded because their behaviour is heterogeneous with regard to normal affixation.

The data mainly come from the two largest Italian dictionaries, the GDIU and the GDLI, and have been further enriched with the help of direct searches on the internet, while derivatives marked as rare, archaic or dialectal were mostly excluded.

\subsection{Maximum derivational networks}

AU: The cross references to figures, tables and equations are highlighted for the author/editor to check and confirm its correct placement. These highlights will be removed in the next stage. Please make changes if necessary.
Table 25.1 displays the maximum derivational networks per order of derivation that are relevant for the saturation value.

Table 25.1: Maximum derivational networks per order of derivation for all three word-classes.

\begin{tabular}{lrrrrr}
\hline & 1st order & 2nd order & 3rd order & 4th order & $\boldsymbol{\Sigma}$ \\
\hline Nouns & 35 & 43 & 11 & 4 & 93 \\
\hline Verbs & 29 & 43 & 28 & 5 & 105 \\
\hline Adjectives & 31 & 24 & 9 & 3 & 67 \\
\hline TOTAL & 95 & 110 & 48 & 12 & 265 \\
\hline
\end{tabular}

Note that the values for derivational networks are roughly similar in the 1st order, but they sharply decrease in the other orders for adjectives, while the opposite is true for verbs and nouns, where the values are even higher in the 2nd order than in the 1st. It is interesting to observe that the value for verbs in the 
3rd order is quite high and in fact similar to that found in the 1st one. At any rate, the values for the 4 th order are quite low for all word-classes.

\subsection{Saturation values}

In this section, the saturation values for the single word-classes are reported as they were elaborated in the general design of the project.

Table 25.2: Saturation values per order of derivation, nouns.

\begin{tabular}{llrrrrr}
\hline Nouns & & $\begin{array}{r}\text { Saturation } \\
\text { value (\%) }\end{array}$ & $\begin{array}{r}\text { 1st order } \\
\text { (\%) }\end{array}$ & $\begin{array}{r}\text { 2nd order } \\
\text { (\%) }\end{array}$ & $\begin{array}{r}\text { 3rd order } \\
\text { (\%) }\end{array}$ & $\begin{array}{r}\text { 4th order } \\
\text { (\%) }\end{array}$ \\
\hline bone & osso & 18.07 & 25.00 & 20.00 & 0.00 & 0.00 \\
\hline eye & occhio & 30.72 & 35.94 & 37.14 & 8.70 & 0.00 \\
\hline tooth & dente & 36.14 & 40.63 & 41.43 & 21.74 & 0.00 \\
\hline day & giorno & 28.92 & 15.63 & 37.14 & 43.48 & 22.22 \\
\hline dog & cane & 11.45 & 25.00 & 4.29 & 0.00 & 0.00 \\
\hline louse & pidocchio & 13.86 & 26.56 & 8.57 & 0.00 & 0.00 \\
\hline fire & fuoco & 48.80 & 39.06 & 51.43 & 52.17 & 88.89 \\
\hline stone & pietra & 19.88 & 32.81 & 17.14 & 0.00 & 0.00 \\
\hline water & acqua & 24.10 & 35.94 & 24.29 & 0.00 & 0.00 \\
\hline name & nome & 18.67 & 18.75 & 18.57 & 21.74 & 11.11 \\
\hline
\end{tabular}

It is interesting to observe that at least one top scorer is found in each of the three word-classes that displays a saturation value neatly surpassing or approximating the half of its derivational capacity: tenere 'to hold' for the verbs and fuoco 'fire' for the nouns, while among the adjectives, lungo 'long' and nuovo 'new' score equally and are closely followed by caldo 'warm'. Moreover, two members of this latter word-class clearly underexploit their capacity, namely angusto 'narrow' and diritto 'straight', with the effect of downsizing the general saturation value of this wordclass with respect to the others. While this barely comes as a surprise given their lower frequency compared to their English correspondents, it is quite striking to observe that the verb dare 'to give' and the noun cane 'dog' score quite low, exploiting about - or even less than - one tenth of their derivational capacity in spite of their high frequency and familiarity. As for dare, this can arguably be 
Table 25.3: Saturation values per order of derivation, verbs.

\begin{tabular}{llrrrrr}
\hline Verbs & & $\begin{array}{r}\text { Saturation } \\
\text { value (\%) }\end{array}$ & $\begin{array}{r}\text { 1st order } \\
(\%)\end{array}$ & $\begin{array}{r}\text { 2nd order } \\
\text { (\%) }\end{array}$ & $\begin{array}{r}\text { 3rd order } \\
\text { (\%) }\end{array}$ & $\begin{array}{r}\text { 4th order } \rightarrow \\
\text { (\%) }\end{array}$ \\
\hline cut & tagliare & 35.80 & 51.92 & 45.90 & 7.69 & 0.00 \\
\hline dig & scavare & 16.05 & 23.08 & 16.39 & 10.26 & 0.00 \\
\hline pull & tirare & 26.54 & 32.69 & 31.15 & 17.95 & 0.00 \\
\hline throw & gettare & 9.88 & 13.46 & 13.11 & 2.56 & 0.00 \\
\hline give & dare & 6.79 & 11.54 & 8.20 & 0.00 & 0.00 \\
\hline hold & tenere & 64.81 & 36.54 & 77.05 & 82.05 & 70.00 \\
\hline sew & cucire & 13.58 & 21.15 & 16.39 & 2.56 & 0.00 \\
\hline burn & bruciare & 16.77 & 26.92 & 16.39 & 7.50 & 0.00 \\
\hline drink & bere & 22.36 & 36.54 & 18.03 & 15.00 & 0.00 \\
\hline know & conoscere & 35.40 & 25.00 & 40.98 & 35.00 & 62.50 \\
\hline
\end{tabular}

Table 25.4: Saturation values per order of derivation, adjectives.

\begin{tabular}{llrrrrr}
\hline Adjectives & $\begin{array}{r}\text { Saturation } \\
\text { value (\%) }\end{array}$ & $\begin{array}{r}\text { 1st order } \\
\text { (\%) }\end{array}$ & $\begin{array}{r}\text { 2nd order } \\
\text { (\%) }\end{array}$ & $\begin{array}{r}\text { 3rd order } \\
\text { (\%) }\end{array}$ & $\begin{array}{r}\text { 4th order } \\
\text { (\%) }\end{array}$ \\
\hline narrow & angusto & 4.65 & 8.33 & 3.13 & 0.00 & 0.00 \\
\hline old & vecchio & 36.05 & 52.78 & 25.00 & 28.57 & 0.00 \\
\hline straight & diritto & 4.65 & 11.11 & 0.00 & 0.00 & 0.00 \\
\hline new & nuovo & 43.02 & 27.78 & 43.75 & 64.29 & 100.00 \\
\hline long & lungo & 43.02 & 44.44 & 56.25 & 21.43 & 0.00 \\
\hline warm & caldo & 39.53 & 33.33 & 43.75 & 50.00 & 25.00 \\
\hline thick & spesso & 25.58 & 30.56 & 31.25 & 7.14 & 0.00 \\
\hline bad & cattivo & 20.93 & 36.11 & 15.63 & 0.00 & 0.00 \\
\hline thin & sottile & 20.93 & 27.78 & 25.00 & 0.00 & 0.00 \\
\hline black & nero & 26.74 & 30.56 & 34.38 & 7.14 & 0.00 \\
\hline
\end{tabular}

related to its reduced phonological size, which makes it a bad derivational basis. On the other hand, for cane, one might tentatively see the reason for its reduced saturation values in the 2nd and 3rd orders in its concrete reference, which is only 
partially exploited in the 1st order to convey more abstract and/or metaphorical meanings, similarly to the other noun pidocchio 'louse', which also scores quite low. Derivatives based on these extended meanings, however, are rarely open to further derivation. In addition, one should also consider the suppletive effect of the learned stems cino- and pediculo-, which are commonly used in terminologies and scientific or technical metalanguages. Concrete references that are rarely expandable metaphorically can also be held responsible for the reduced derivational capacity of the verb cucire 'to sew', while for gettare 'to throw', the competition with its near-synonym lanciare 'to launch, throw' can be invoked. At any rate, in the following table, the average saturation values per order of derivation are reported for all three word-classes.

On average, the values are quite homogeneous across the three word-classes.

Table 25.5: Average saturation values per order of derivation for all three word-classes.

\begin{tabular}{lrrrr}
\hline & 1st order & 2nd order & 3rd order & 4th order \\
\hline Nouns & 29.53 & 26.00 & 14.78 & 12.22 \\
\hline Verbs & 27.88 & 28.36 & 17.75 & 15.00 \\
\hline Adjectives & 30.28 & 27.81 & 17.86 & 12.50 \\
\hline
\end{tabular}

\subsection{Orders of derivation}

In the following table, the difference between the richness of nouns and verbs as derivational bases clearly stands out against the reduced derivational capacity of adjectives.

Table 25.6: Maximum and average number of orders of derivation for all three word-classes.

\begin{tabular}{lrr}
\hline & Maximum & Average \\
\hline Nouns & 8 & 2.33 \\
\hline Verbs & 9 & 2.63 \\
\hline Adjectives & 6 & 1.69 \\
\hline
\end{tabular}




\subsection{Derivational capacity}

This difference is also reflected in the following two tables, in which the maximum and the average derivational capacities for the three word-classes are reported with regard to the 1st order derivatives for all three word-classes.

Table 25.7: Maximum and average derivational capacity for all three word-classes.

\begin{tabular}{lrr}
\hline & Maximum & Average \\
\hline Nouns & 26 & 18.9 \\
\hline Verbs & 27 & 14.5 \\
\hline Adjectives & 19 & 10.9 \\
\hline
\end{tabular}

Table 25.8: Average number of derivatives per order of derivation for all three word-classes.

\begin{tabular}{lrrrr}
\hline & 1st order & 2nd order & 3rd order & 4th order \\
\hline Nouns & 18.9 & 18.2 & 3.4 & 1.1 \\
\hline Verbs & 14.5 & 17.3 & 7.1 & 1.2 \\
\hline Adjectives & 10.9 & 8.9 & 2.5 & 0.5 \\
\hline
\end{tabular}

\subsection{Correlation between semantic categories and orders of derivation}

There seems to be a certain correlation between saturation value and paradigmatic strength - the latter expressed by the total number of derivatives of the 1st order - in the 2nd order for all three word-classes $\left(\mathrm{N}_{2 \mathrm{nd}}=0.46, \mathrm{~V}_{2 \mathrm{nd}}=0.62\right.$, $\left.\mathrm{A}_{2 \text { nd }}=0.63\right)$, while the correlation weakens and even becomes negative in the other orders $\left(\mathrm{N}_{3 \mathrm{rd}}=-0.03, \mathrm{~V}_{3 \mathrm{rd}}=0.34, \mathrm{~A}_{3 \mathrm{rd}}=0.34 ; \mathrm{N}_{4 \text { th }}=0.19, \mathrm{~V}_{4 \text { th }}=0.17\right.$, $\left.\mathrm{A}_{4 \text { th }}=-0.05\right)$. This confirms the expectation that Italian apparently does not like long chains of affixes exceeding the 2nd order of derivation (cf. Gaeta 2005). Notice that the less robust correlation value obtained for nouns arguably depends on the low derivational capacity of cane and pidocchio discussed above. 
Semantic categories typical of the 1st order of derivation are AUGMENTATIVE (present in 10 lexemes) MANNER (9), and DIMINUTIVE (7). It must be added that the other semantic category typical of adjectives in the 1st order is ABSTRACTION (10), but the suffixes mainly used to form abstracts, namely -ità and -ezza, are only marginally open to further derivation (cf. Gaeta 2005). This means that only verb-forming semantic categories, namely CAUSATIVE (6) and INCHOATIVE (3), provide bases which are further derived in the 2nd order for semantic categories like ACTION (8), ABILITY (7), AGENT (6), INSTRUMENT (5) and AGENT/FEMALE (4) with the addition of the semantic category MANNER (8), which is normally combined with bases displaying the elative suffix -issimo discussed above. Note the frequent occurrence of the conjoined categories AGENT/FEMALE, which is due to the highly productive suffix -trice (e.g. nuovo 'new' > innovare 'to innovate' > innovatrice 'innovator (fem.)'; cf. Gaeta 2010).

The picture for nouns and verbs is radically different. With regard to nouns, besides those relating to evaluative suffixes, namely DIMINUTIVE (10), AUGMENTATIVE (10) and PEJORATIVE (8), we observe a rich number of semantic categories typical of the 1st order which are distributed across different output word-classes: RELATIONAL (8), PRIVATIVE (7), QUALiTY (7), AGENT (6), COLlECTIVE (6), LOCATION (6), ORNATIVE (6), Singulative (6), CAUSATIVE (5) and InSTRUMENT (5). This is reflected in 2nd order derivatives relating to semantic categories like ACTION (10), ABSTRACTION (7), AGENT (6), MANNER (6), ABILITY (5) and DIMINUTIVE (5). As for verbs, the semantic categories typical of the 1st order are ACTION (10), AGENT (10), ABILITY (9), AGENT/FEMALE (9), ITERATIVE (8), INSTRUMENT (7), DiminUTIVE (6) and RESUltATIVE (6), which are reflected in 2nd order derivatives relating to semantic categories like ABILITY (10), ABSTRACTion (10), ACTiON (9), AGENT (8), AGENT/FEMALE (8), and INSTRUMENT (6), which again give rise to 3rd order derivatives relating to ABSTRACTION (8) and, less typically, to ACTION (3) and AUGMENTATIVE (3).

\subsection{Semantic categories with blocking effects}

A certain number of factors of different natures can be held responsible for constraints on the derivational capacity of the lexemes. One factor of a phonological nature is the length of the base, as already pointed out for dare. Another factor is of a categorial nature, being connected either to the properties of a certain word-class or of a certain class of affixes. In this regard, the immensely productive suffix -mente, which is also the only suffix that forms adverbs, systematically excludes any further suffixation: posteriore 'posterior' > posterior-mente 'posterior-ADV' > * posteriorment-eggiare (on productivity in Italian 
word-formation, cf. Gaeta and Ricca 2006). In terms of the derivational network adopted here, this restriction must be seen as a closing effect of the semantic category MANNER, which hampers any further derivation. More generally, adverbs are seldom possible bases of derivation: minor exceptions include subito 'immediately' > subit-aneo 'sudden', indietro 'backwards' > indietr-eggiare 'to move backwards' $j$ ?r 'sto 'soon' > *prest-aneo, and avanti 'forwards' > *avant-eggiare. The limited derivational capacity of diritto observed above also has to be seen from this viewpoint, since it is mainly used as an adverb.

On the other hand, the immense productivity of -mente must cede to bases displaying evaluative suffixes that generally hamper further derivations: bello 'beautiful' > bell-ino 'beautiful-DIM' > *bellina-mente, caldo 'warm' > cald-uccio 'warm-DIM' > *calduccia-mente, cattivo 'bad' > cattiv-one 'bad-AUG' > *cattivonamente, etc., unless a morphopragmatic trait [non-serious] is involved in the utterance, as in Manzoni's coinage lungh-etta-mente 'long-DIM-ADV'. Remarkably, the elative suffix -issimo does normally form adverbs: cattiv-issima-mente 'badAUG-ADV', lungh-issima-mente 'long-AUG-ADV', etc. The closing effect is not limited to -mente, but appears to be a general property of evaluative suffixes: bellino > *bellin-ezza, dolce 'sweet' > dolci-astro 'sweet-PEJ' > *dolciastr-ificare, etc. Again, in the terms adopted here, this restriction has to be seen as a closing effect of the semantic categories relating to evaluative meaning, namely DIMINUTIVE, AUGMENTATIVE (with the mentioned exception of -issimo) and PEJORATIVE.

\subsection{Typical combinations of semantic categories}

A number of chain-effects witnessing the derivational potential of the system can be observed, which are arguably related to the selective properties of the single affixes with regard to the input/output of the word-class.

- CAUSATIVE/ITERATIVE-ABILITY-ABSTRACTION: e.g. caldo 'warm' > scaldare 'to warm (up)' > scaldabile 'warmable' > scaldabilità 'warmability'; cucire 'to sew' > ricucire 'to re-sew' > ricucibile 're-sewable' > ricucibilità 're-sewability' (overall 7 cases)

- ABILITY-ABSTRACTION/PRIVATIVE-MANNER/ABSTRACTION: e.g. conoscere 'to know' > conoscibile 'knowable' > conoscibilità 'knowability' / inconoscibile 'unknowable' > inconoscibilmente 'unknowably' / inconoscibilità 'unknowability' (overall 7 cases)

- RELATIONAL-CAUSATIVE-ABSTRACTION(/ABILITY-ABSTRACTION): e.g. fuoco 'fire' > focale 'focal' > focalizzare 'to focalize' > focalizzazione 'focalization' / focalizzabile 'focalizable' > focalizzabilità 'focalizability' (overall 3 cases) 
- QUALITY-PRIVATIVE-MANNER: e.g. dente 'tooth' > dentato 'toothed' > sdentato 'toothless' > sdentatamente 'toothlessly' (overall 3 cases)

These chains exploit the high productivity of verb-forming procedures as well as of certain affixes and affix combinations reflected in semantic sequences like ABILITY-ABSTRACTION and ABILITY-PRIVATIVE, which occur 43 and 13 times respectively in the sample.

\subsection{Multiple occurence of semantic categories}

Cases of multiple occurrences of the same semantic category are negligible, on the whole.

\subsection{Reversibility of semantic categories}

This phenomenon is non-existent in Italian.

\subsection{Conclusions}

To sum up, in Italian, the first two orders are considerably crowded with regard to the others, while no 5th order derivations occur. Verbs and nouns (in this order) clearly exhibit the highest number of derivational networks compared to adjectives, probably because of the closing effect of evaluative meanings (DIMINUTIVE, PEJORATIVE and, to an extent, AUGMENTATIVE) and of other semantic categories like MANNER and, to an extent, ABSTRACTION, which are particularly common with adjectives, especially in the 1st order. As a consequence, while the value for derivational networks of adjectives is quite high in the 1st order and sharply decreases in the others, the opposite is true for verbs and nouns, where the values are even higher in the 2nd order than in the 1st (Tables 25.1, 25.7 and 25.8). This is confirmed by the maximum and average number of orders of derivation, which are clearly lower for adjectives than the equivalent figures found for verbs and nouns (Table 25.6). In contrast, since the limits on the derivational capacity of adjectives result from the closing effects of certain meanings typically occurring in the 1st order, no repercussions are observed on the saturation value, which reflects the degree of actualization of the semantic categories that 
are activated at any order of derivation. In fact, similar values are obtained for all word-classes (Table 25.5), with the exception of nouns, where some misalignment has to be recorded (Table 25.2), probably because of the idiosyncratic properties of single lexemes that are due to the reduced size of the base or to the suppletive effect of learned stems.

\section{References}

Gaeta, Livio. 2000. On the Interaction between Morphology and Semantics: The Italian Suffix-ATA. Acta Linguistica Hungarica 47 (1-4). 205-229.

Gaeta, Livio. 2003. Produttività morfologica verificata su corpora: il suffisso -issimo. In Franz Rainer \& Achim Stein (eds.), I nuovi media come strumenti per la ricerca linguistica, 43-60. Frankfurt/Main: Peter Lang.

Gaeta, Livio. 2005. Combinazioni di suffissi in italiano. In Maria Grossmann \& Anna M. Thornton (eds.), La formazione delle parole, 229-247. Roma: Bulzoni.

Gaeta, Livio. 2010. On the viability of cognitive morphology for explaining language change. In Alexander Onysko \& Sascha Michel (eds.), Word Formation from Cognitive Perspectives, 75-95. Berlin \& New York: Mouton de Gruyter.

Gaeta, Livio \& Davide Ricca. 2006. Productivity in Italian word-formation: A variable-corpus approach. Linguistics 44 (1). 57-89.

GDIU = De Mauro, Tullio (ed.). 1999. Grande Dizionario Italiano dell'Uso, 8 volumes. Turin: UTET.

GDLI = Battaglia, Salvatore et al. (1964-2009). Grande Dizionario della Lingua Italiana, 23 volumes. Turin: UTET.

Grossmann, Maria \& Franz Rainer (eds.). 2004. La formazione delle parole in italiano. Tübingen: Niemeyer.

Iacobini, Claudio. 2004. Prefissazione. In Maria Grossmann \& Franz Rainer (eds.), La formazione delle parole in italiano, 97-163. Tübingen: Niemeyer.

Luraghi, Silvia. 1999. Il suffisso -ante/ente in italiano: fra flessione e derivazione. In Paola Benincà, Alberto Mioni \& Laura Vanelli (eds.), Fonologia e Morfologia dell'italiano e dei dialetti d'Italia, 539-550. Roma: Bulzoni. 